\title{
Improving Distributed Decision Making in Inventory Management: A Combined ABC-AHP Approach Supported by Teamwork
}

\author{
Ileana Gloria Pérez Vergara, ${ }^{1}$ Julián Andrés Arias Sánchez, ${ }^{2}$ Rocío Poveda-Bautista ${ }^{(\mathbb{D}},{ }^{3}$ \\ and Jose-Antonio Diego-Mas $\mathbb{B D}^{4}$ \\ ${ }^{1}$ Facultad de Ingeniería, Universidad de San Buenaventura, Cali, Colombia \\ ${ }^{2}$ Facultad de Ingeniería, Universidad del Valle, Cali, Colombia \\ ${ }^{3}$ INGENIO (CSIC-UPV), Institute of Innovation and Knowledge Management, Universitat Politècnica de València, \\ Valencia, Spain \\ ${ }^{4} \mathrm{I3B}$, Institute for Research and Innovation in Bioengineering, Universitat Politècnica de València, Valencia, Spain
}

Correspondence should be addressed to Rocío Poveda-Bautista; ropobau@upvnet.upv.es

Received 11 March 2019; Revised 24 January 2020; Accepted 29 January 2020; Published 19 February 2020

Guest Editor: Marin Lujak

Copyright (c) 2020 Ileana Gloria Pérez Vergara et al. This is an open access article distributed under the Creative Commons Attribution License, which permits unrestricted use, distribution, and reproduction in any medium, provided the original work is properly cited.

\begin{abstract}
The need of organizations to ensure service levels that impact on customer satisfaction has required the design of collaborative processes among stakeholders involved in inventory decision making. The increase of quantity and variety of items, on the one hand, and demand and customer expectations, on the other hand, are transformed into a greater complexity in inventory management, requiring effective communication and agreements between the leaders of the logistics processes. Traditionally, decision making in inventory management was based on approaches conditioned only by cost or sales volume. These approaches must be overcome by others that consider multiple criteria, involving several areas of the companies and taking into account the opinions of the stakeholders involved in these decisions. Inventory management becomes part of a complex system that involves stakeholders from different areas of the company, where each agent has limited information and where the cooperation between such agents is key for the system's performance. In this paper, a distributed inventory control approach was used with the decisions allowing communication between the stakeholders and with a multicriteria group decision-making perspective. This work proposes a methodology that combines the analysis of the value chain and the AHP technique, in order to improve communication and the performance of the areas related to inventory management decision making. This methodology uses the areas of the value chain as a theoretical framework to identify the criteria necessary for the application of the AHP multicriteria group decision-making technique. These criteria were defined as indicators that measure the performance of the areas of the value chain related to inventory management and were used to classify ABC inventory of the products according to these selected criteria. Therefore, the methodology allows us to solve inventory management DDM based on multicriteria ABC classification and was validated in a Colombian company belonging to the graphic arts sector.
\end{abstract}

\section{Introduction}

Nowadays, the level of business competitiveness has to be high when facing the opening of markets as an intrinsic factor of globalization. It is necessary for companies to be competitive to respond to the requirements of increasingly demanding customers in terms of cost, quality, and product delivery time. Likewise, small and medium-sized enterprises (SMEs) must compete with multinationals belonging to the same sector, which have a greater infrastructure, in terms of processes and finance strength, which means that SMEs need to increase productivity levels through decision models.

Being able to develop competitive advantages with customer service orientation allows companies to excel in 
local and foreign markets. Therefore, it is important to carry out an internal analysis of the company's processes, which should be focused on achieving the satisfaction of internal and external customers, as well as guaranteeing the best performance in the operation.

The decisions related to inventory management are especially relevant in a customer service orientation approach. These decisions are part of a complex system and involve stakeholders from different areas of the company, where each agent has only limited information and where the cooperation among such agents is key for the system's performance. The most used tool for the identification of these stakeholders, and to model this complex system, is the analysis of the value chain. In addition, the value chain provides a framework for identifying the criteria to be considered [1] in decision-making inventory management through all areas of the company. On the other hand, even though, from a centralized point of view, these inventory management decisions are interesting topics to investigate, we are going to approach these issues within the distributed decision-making (DDM) framework that considers all areas of the value chain.

Several DDM structures are possible within this scenario. In this work, a single-level distributed inventory control approach was used with the decisions made by the stakeholders involved at the management team level, allowing communication and coordination among the decision makers with a multicriteria group decision-making perspective.

It is important to highlight that the objective of this research work is to propose a methodology that integrates value chain analysis and a multicriteria decision-making method. This methodology tends to identify and improve the relationship among the stakeholders involved in one of the most important logistics processes for companies, such as inventory management.

This research was validated in a Colombian company belonging to the graphic arts sector. This sector is shown to have a big influence in the national economy due to its contribution of $3.7 \%$ of GDP in Colombia. Therefore, any effort that tends to improve the competitiveness of this sector will reflect directly on the economy of the region and later on the economic and commercial position of Colombia.

Due in large part to the expansionist trend that this sector has undergone in recent years, especially in the cities of Bogotá, Medellín, and Cali, companies have focused efforts on the acquisition of specialized software for production planning, acquisition of equipment for manufacturing processes, and human resources expansion. However, the efforts associated with the development and analysis of the value chain considering multicriteria decisions for inventory management have not been appreciated. This generates a problematic environment for the decisions made on how to control the inventory by the stakeholders.

One of the main pieces of evidence of this problem, in the SMEs of graphic arts, is the noncompliance with the delivery dates agreed with the clients. There is also a high level of obsolescence of stocks. This situation is largely caused by the lack of inventory policies that should allow the identification of when and how many product units to order from suppliers. Additionally, as mentioned in [2], the process of decision making in inventory management is complex, which is why different perspectives are needed from the department managers of each area of the company to control stocks in a more efficient way. In this regard, several research works have been undertaken focused on methodologies based on multiple criteria for inventory planning and control taking into account, i.e., cost, quality, and delivery $[3,4]$. This will be addressed in the following sections of this article.

As mentioned at the beginning of the section, the purpose of this paper is to propose a methodology for value chain analysis that considers multicriteria decisions for inventory management. This methodology allows us, in the first instance, to consider an internal analysis of the company's value chain that recognizes the relevance of decision-making processes in inventory management. At the same time, it allows us to identify the best criteria to classify and control the inventory based on the opinions of the stakeholders involved in the process. Finally, the methodology establishes the guidelines of an ABC classification based on the multicriteria technique analytic hierarchy process (AHP) [5] in order to categorize items correctly.

In Section 2 of this article, the theoretical foundations of the proposal are presented. In Section 3, the methodology proposed by the authors will be explained, and each of its components will be described. In Section 4, the process of planning and inventory control in the company is characterized. In the same section, the validation of the methodology, being applied to a Colombian graphic arts company, was shown. In the two last sections, we present the conclusions of the research, limitations, and recommendations for future research work on the subject.

\section{Literature Review}

2.1. Value Chain. Organizations grant a set of physical and intangible features and benefits to customers. These are the result of a logical and progressive process that, when carried out efficiently, achieves one of the main objectives of the entire company: customer satisfaction, also known as value approach [6].

The value chain is considered as a technique for the analysis of manufacturing and service companies that determines how an organization can develop and deliver value to its stakeholders, customers (both internal and external), through the analysis and identification of sources of value for the optimization of adjacent processes. According to some previous works [6-9], the synthesis of business activity is divided into two types of activities: the primary and secondary. The primary activities are associated with the manufacture, transfer, and sale of the products to the buyer. On the other hand, the secondary activities are related and serve as support for the previous ones, such as procurement, information systems, and communications among others. Figure 1 shows the generic scheme by types of activities that make up the value chain. 


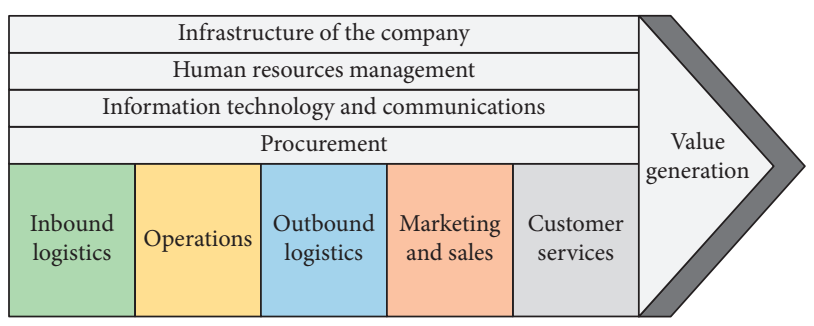

FIgURE 1: Value chain structure [6].

The final part of the chain represents the margin or profit, which is seen as the intangible increase in the value appreciated by internal customers (company areas) or external customers (end users).

The value chain of the companies, which covers all its functions, consists of suppliers, purchases, operations, marketing, sales, customers, human resources, and finances depending on the products and services provided [10]. The analysis of the components of the value chain allows us to define the factors that most affect company competitiveness [11]. In this sense, business analysis is based on the analysis of the company's value chain.

The value chain can be defined as a conceptual structure, and its components can be used to lay the foundations for the company's performance in inventory management, identifying the main criteria for this purpose. Value chain analysis helps to diagnose the sources of information and communication in inventory management. Therefore, the value chain will be used as a conceptual framework to identify the areas related to inventory management, involving stakeholders in decision-making processes, increasing communication and coordination with each other, and improving the performance of these areas in inventory management.

2.2. Multicriteria ABC Classification. Traditionally, companies often use the well-known $A B C$ classification technique to identify the most representative inventory items and, at the same time, have an efficient control over them. Companies handle a large number of inventory items, which makes the management and control process more complex given the limited amount of resources. To have an efficient inventory management, the most appropriate action is to group the stock and to focus on the most important items [12].

The ABC classification, which is based on the Pareto principle, has three classes or families of products: class $\mathrm{A}$, including the most important articles, class $\mathrm{B}$ that are of moderate importance, and class $\mathrm{C}$ that have a low importance. Consequently, once the classes are established among the articles, control policies can be defined as those presented by Silver et al. [13].

Traditional methods only consider one criterion, commonly the unit cost of acquisition. This is largely due to the fact that companies have been focused on analysing the products that generate the greatest sensitivity to cash flows and to the profitability of the operation. However, in the literature, inventory classification approaches are portrayed under multiple criteria, known as multicriteria inventory classification (MCIC). Some previous works [14-17] illustrate the implementation of these methodologies.

According to the literature review carried out by Van Kampen et al. [18], in many bibliographic studies, multicriteria techniques have been proven to be a good alternative to help control and classify inventory items. The use of the AHP is especially addressed in these studies [14, 19-22], since its structure deals with the subjectivity of the experts about the pronouncement of judgments [17].

On the other hand, several authors follow two main trends to determine the thresholds for the classification of products in each category A, B, or C, (i) those that set them on a percentage basis of the quantity of products, most of them based on ranking methods $[19,23-26]$, and (ii) those who propose them based on advanced methods, such as sorting methods or artificial intelligence (AI) methods [27-33]. The choice of the path forward will depend on the skill and knowledge of the experts, since, in practice, accurate data and criteria affecting $\mathrm{ABC}$ classification are not always available. Therefore, many times, managers prefer linguistic values than numerical values for measuring the criteria in practical applications of $\mathrm{ABC}$ classification. These linguistic values are closer to the knowledge and experience of the experts. Hence, in the literature, there are many applications of type (i). In these applications, the authors handle various percentage values for classification and there is no prevalence of specific classification percentages for categories A, B, and C. One of the most frequently used classifications is 20,30 , and $50 \%$ for products $\mathrm{A}, \mathrm{B}$, and $\mathrm{C}$, respectively $[26,34]$.

2.3. Analytic Hierarchy Process (AHP) in Inventory Management Distributed Decision Making. Distributed decision making (DDM) addresses an important and rapidly developing field in general decision theory. It comprises several areas among other group decision making [35].

Classical decision theory and decision analysis are centralized, i.e., there is only one decision maker with a utility function and a set of subjective probabilities about the state of the world. The presence of multiple decision makers makes the problem more complicated because the decision makers may have different utility functions and/or different assumptions about the underlying uncertainty. Even when all the decision makers have the same point of view and are going to make their decisions cooperatively, there is still the problem of defining optimality for multiple utility functions. One approach is given by multiattribute utility theory where an organizational utility function is constructed from the individual utilities. Another approach is given by team decision theory, which considers decision making by multiple decision makers with a single common objective but different information about the underlying uncertainty. Physically, one may imagine the decision makers to be connected by a communication network that is imperfect.

Following Schneeweiss [36] and his classification proposal, decision problems with various decision-making units (DMUs) and team-based DDM systems are like one-party 
systems and are denoted as conflict-free DDM problems. In these cases, the team has the same utility function and just one coordinating decision must occur. This requires a DDM system of partners to be symmetrically informed.

Saaty [5] developed the analytic hierarchy process (AHP), a mathematical technique based on matrix concepts, which allows solving complex problems in convergence terms of human judgments. AHP is a multicriteria decisionmaking technique that can be included in the multiattribute utility theory [37] and whose application, widely extended in various fields, is also used in group decision making [38].

In the process of decision making in inventory management, it can be considered that all the stakeholders, although with different information and perspectives depending on the area of the company to which each one belongs, form a single DMU (management team). This is because they share the same objective in terms of inventory management. In this way, this issue can be treated as a case of multicriteria group decision making.

According to Saaty [39], there are two important issues in group decision making: how to add individual judgments in a group in a single representative judgment for the whole group and how to build a group choice based on individual choices. The reciprocal property plays an important role in combining the judgments of several individuals to obtain a unique judgment for the group. The judgments must be combined so that the reciprocal of the synthesized judgments is equal to the synthesis of the reciprocals of these judgments. It has been shown that the geometric mean, not the arithmetic mean used frequently, is the only way to do it. If individuals are experts, they may not want to combine their judgments, but only the results obtained by each from their own preferences. In that case, the geometric mean of the final results is taken.

\subsubsection{Theoretical Background of the Analytic Hierarchy} Process (AHP). The AHP technique formalizes and makes a systematic decision-making process, which is largely subjective and, therefore, facilitates "precise" judgments. As a result of the method, the decision makers receive information of the implicit weights of the evaluation criteria. AHP allows better communication, leading to a clearer understanding and consensus among the members of the decision-making groups and therefore a greater commitment to the chosen alternative. This method has the following steps:

Identification of the problem: before starting any numerical calculation, it should be checked that the problem in question can be displayed as a structured model, where the criteria and the alternatives of the process are identified. At the top level of the structure, the objective or goal of the decision problem to be solved must be identified.

Selection of criteria: in this stage, the criteria associated with the multicriteria decision-making process are selected, which will be assessed and weighted in subsequent stages. Some criteria for the classification of inventory items addressed in the literature are presented in Table 1. It is important that accurate data of the criteria are available, since a satisfactory result of the process depends on it.

Pairwise comparison of criteria: each criterion $i$ is compared to criterion $j$ through the relative scale of priority presented in Table 2: Saaty's 1-9 scale [46]. Such comparisons are located in a square matrix of order $n$ and reciprocal. This process is repeated with each of the experts and stakeholders involved in the assessment process.

Priority calculation: the weights of each one of the criteria are calculated through

$$
A \omega=\lambda_{\max } \omega,
$$

where $A$ is a $n$ dimensional of the comparison matrix, $\lambda_{\max }$ is the largest eigenvalue of $A$, and $\omega$ is the eigenvector corresponding to $\lambda_{\max }$.

Consistency index: equation (2) is used to calculate the consistency of the decision-making process.

$$
\text { C.I }=\frac{\left(\left(\lambda_{\max }-n\right) /(n-1)\right)}{\text { R.I }},
$$

where $n$ is the number of the criteria and R.I is a random index corresponding to the $n$ criteria. Table 3 shows the variation of the R.I according to $n$.

Coefficient of consistency: this coefficient measures the degree of homogeneity between the judgments issued by the experts or stakeholders of the process. $A$ value less than 0.1 is considered admissible. However, when more than 5 criteria are handled within a multicriteria decision-making process, this threshold can increase to 0.15 or 0.18 . To calculate it, use

$$
\text { C.C }=\frac{\text { C.I }}{\text { R.I }}
$$

\subsubsection{The Use of Multicriteria Analysis in Value Chain and} Inventory Classification. In order to achieve a level of efficiency in the logistics activities of the value chain, aligned with the competitive tendencies of the industrial market, these activities must be supported by multicriteria methodologies for decision making. For example, for the selection and evaluation of suppliers, there are diverse applications such as the following $[47,48]$.

It is important to note that efforts have also been focused on applying multicriteria techniques for the distribution of products, such is the case of the research work presented by Bravo et al. [49]. This work shows a distribution prioritization methodology that considers several criteria when making shipments to customers. For this purpose, the AHP method was used to weigh criteria and to determine which are the most important when are making operational distribution decisions.

In the research work carried out by Guarnieri et al. [50], a reference framework is presented for the hiring of a $3 \mathrm{PL}$ 


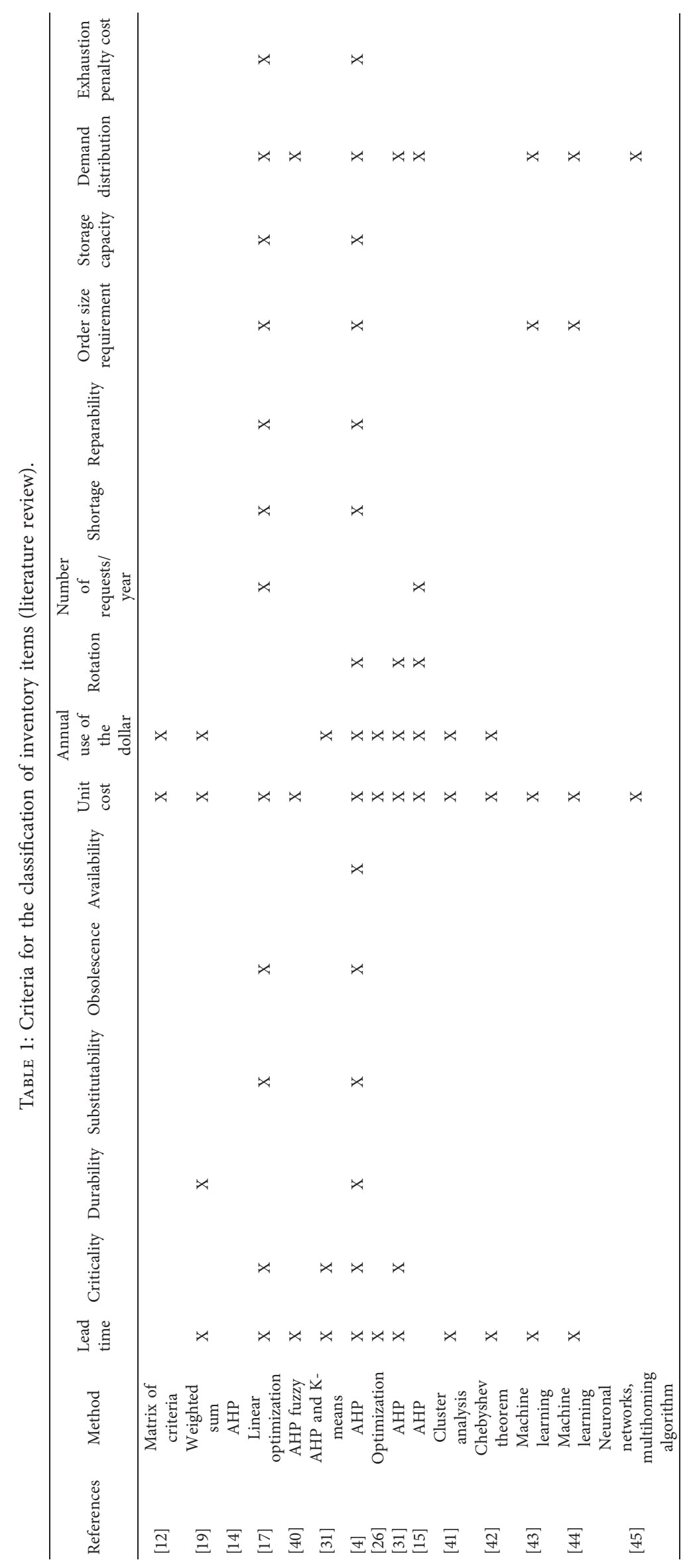


TABLE 2: Scale intensity of relative importance [5].

\begin{tabular}{lc}
\hline Value $a_{i j}$ & Description \\
\hline 1 & Criterion $i$ and criterion $j$ are considered \\
to be equally important \\
3 & Criterion $i$ is considered to be slightly \\
more important than criterion $j$ \\
5 & Criterion $i$ is considered to be significantly \\
more important than criterion $j$ \\
7 & Criterion $i$ is considered to be far more \\
& important than criterion $j$ \\
9 & Criterion $i$ is considered to be absolutely \\
$2,4,6,8$ & more important than criterion $j$ \\
\hline
\end{tabular}

TABLE 3: Scale of variation of the random index [5].

\begin{tabular}{lc}
\hline Number of criteria $(n)$ & Random index \\
\hline 2 & - \\
3 & 0.58 \\
4 & 0.90 \\
5 & 1.12 \\
6 & 1.24 \\
7 & 2.32 \\
8 & 1.41 \\
9 & 1.45 \\
\hline
\end{tabular}

supplier of reverse logistics, 3PRPL-third-party reverse logistics supplier, taking into account environmental regulations. Several multicriteria techniques are proposed for the selection of suppliers, among which the use of AHP stands out.

Decision making in inventory management from a multicriteria analysis has been widely studied in the literature. The first contribution on MCIC was provided in [19] that applied AHP to classify inventory items. Later, AHP was adopted by some authors such as [14, 22], and others have used modified versions of AHP applied in MCIC, for instance, AHP Fuzzy [40], or a new hybrid method based on AHP and the $K$-means [31]. Several authors have used AHP for spare parts classification $[20,21,32]$.

MCIC is a specific issue that can be faced with the application of AHP, where the alternatives correspond to the inventory items $[19,31]$, since AHP can solve problems with qualitative and quantitative evaluations. These evaluations are entered into a pairwise comparison matrix. The importance of the criteria and ranking of the alternatives are then derived with the eigenvalue $[5,51]$. As the value of the items on each criterion in MCIC is often precisely measureable [19], these values are normalised in order to be combinable and rankable in a weighted global score.

Nowadays, only a few applications on machine learning classification algorithms to MCIC have been developed $[44,52]$, and the only one which has been extended to the inventory system is the study carried out by Lolli et al. [43]. These applications can reduce classification cost and human errors when sets of thousands of inventory items must be managed.

By carrying out a thorough bibliographic analysis, the most commonly used criteria in the literature for the classification of inventory items were identified, as shown in Table 1.

\section{Proposed Methodology}

3.1. Basic Foundations of the Methodology. The main objective of this work is to propose a methodology that combines the analysis of the value chain and the AHP multicriteria decision-making technique, in order to improve the communication and the performance of the areas related to the inventory management decisionmaking process. The criteria used in the decision-making process will be those indicators that allow us to analyse the performance of the areas of the value chain related to inventory management. On the other hand, with the application of AHP, it is possible to solve inventory management DDM based on multicriteria $\mathrm{ABC}$ classification.

Before performing an analysis of the value chain, it becomes relevant to know the level of maturity of the company to identify the processes that are not aligned with the objectives and interests of the organization. In this way, a qualitative analysis of the level of communication and coordination among the areas that make up the value chain is carried out. Once this level has been identified, it is necessary to define the performance in the processes of each area related to inventory management. For this purpose, indicators that analyse this performance are established.

Therefore, to achieve this objective, the methodology is based on three key aspects:

Maturity level of the company: according to AlonsoManzanedo et al. [53], the maturity level of the company can be set in 5 levels as shown in Table 4 .

Definition and evaluation of performance measurement: according to Augusto et al. [54], companies should possess a model that measures the characteristics and parameters of multifaceted performance through a number of specific indicators approved by experts. Performance indicators allow us to identify how close or far is the proposed goal. However, there are two common problems when measuring the performance of a process: the first is that a goal is difficult to obtain due to the lack of information or communication of the stakeholders. To this end, a level 3 of maturity of the company, which is considered necessary to establish coordinated decisions in inventory management, must be reached. This level is an achievable one for any organization that considers common objectives in decision making. The second problem is the poor mathematical construction of the indicators. This is frequent when the stakeholders have little expertise in the work context. It is important that the members of each area of the organization have knowledge of the inputs, processing, and outputs required by the inventory management process and know how to connect with the other areas.

Value chain framework: once the two previous steps have been completed, it is proposed to carry out the 
TABLE 4: Maturity level of a company [53].

\begin{tabular}{|c|c|}
\hline Level & Description \\
\hline 1 & $\begin{array}{l}\text { The processes are unstructured and address } \\
\text { the interests of each area }\end{array}$ \\
\hline 2 & $\begin{array}{l}\text { The processes are defined and documented } \\
\text { and the relationships among areas are based } \\
\text { only on the transfer of information }\end{array}$ \\
\hline 3 & $\begin{array}{c}\text { There is feedback from each area leader and } \\
\text { the objectives are shared }\end{array}$ \\
\hline 4 & $\begin{array}{c}\text { The members of the organization collaborate } \\
\text { in other processes and not only information } \\
\text { is shared but also resources }\end{array}$ \\
\hline 5 & $\begin{array}{l}\text { There is reciprocal trust and mutual dependence } \\
\text { among the members of an organization to achieve } \\
\text { common objectives }\end{array}$ \\
\hline
\end{tabular}

analysis of the value chain together with the multicriteria decision-making technique as the central basis of the methodology. The proposed methodology will use the areas of the value chain as a theoretical framework to identify the criteria necessary for the application of the AHP multicriteria group decisionmaking technique. To this end, all the areas of the value chain are analysed in order to identify the stakeholders involved in inventory management and the performance indicators, which will be the criteria in the AHP model. These criteria were defined taking into account the literature review shown in Table 1 and the opinion of all the stakeholders involved in inventory management as experts in these decision-making processes.

As a main goal when defining performance indicators in inventory management, it was established to maximize compliance with the service level of the inventory items (the goal of the decision-making problem in the AHP model). On the other hand, to help the mathematical construction of the combination of indicators that measure the performance of these areas, it is proposed to complement the methodology with the use of AHP (see Section 2.2), which establishes how these criteria should be weighted when classifying inventories. In Figure 2, this methodology is related.

3.2. Flowchart of the Methodology. As shown in Figure 2, the methodology begins with the identification of the level of maturity of the organization. It is important that problems that exist in the company are identified in terms of lack of communication among the areas, failure to meet common objectives for the company, and loss of trust among the members of each area.

Next, consensus meetings should be scheduled in which each of the stakeholders reviews their capacities, limitations, and opinions about the process. The consensus meetings should be held periodically and should measure the progress and commitments proposed by each area. All of the stakeholders, as DDM system partners, have to share information and have to be symmetrically informed. In this type of meetings, work must be done to improve communication and coordination until reaching the level of maturity necessary for the organization (level 3).
3.2.1. Value Chain Analysis. In this step, performance indicators that have an impact on inventory management for each of the areas of the value chain are established so that their measurement considers relevant elements for the areas with which they are related. For example, the customer service area must handle a cumulative service level indicator that not only considers the dates and quantities agreed with the customer but also considers the level of service provided by the raw material inventory (logistics area) and tracks when stock breakage occurs.

When these requirements are achieved, a thorough analysis of the value chain is carried out in order to identify experts from all the necessary areas. In this sense, all processes that add value to the company should be considered. For the specific case of inventory management, all the internal and external processes shown in Figure 1 are taken into account: the procurement section must issue orders to suppliers, inbound logistics must receive, store, and control all the items of inventory, and outbound logistics must distribute the product according to the location of customers.

Finally, when the company obtains the results of the analysis of the value chain, different improvement actions are proposed that intend to add greater value to the company.

3.2.2. AHP Method. Following Flores et al. [19], the methodology applies an AHP-based approach (see Saaty [5]) that synthesises several weighted criteria into a single priority score for each item. The values of the items on each criterion in MCIC are normalised in order to be commensurable and combinable in a weighted global score.

Following the steps of the AHP method, the opinions of each of the experts are considered and consensus criteria are selected by these stakeholders as those indicators that are capable of measuring performance in all areas of the value chain. These criteria will be extracted from the set of criteria proposed by the literature, shown in Table 1, in order to classify the inventory items. Next, the iterations corresponding to the AHP are performed, raising the pairwise comparison matrix to limiting powers, and the weights of each criterion are obtained through the aggregation of the experts' judgments by means of the geometric mean. Mathematical foundations and the steps of the AHP technique can be found in [5].

In the final step of the methodology, the classification of the inventory items in the classes defined as A, B, and C is carried out by means of weighted sum, obtaining a single priority score for each item [19].

As mentioned in Section 2.2, one of the most frequently used classifications is 20,30 , and $50 \%$ for products $\mathrm{A}, \mathrm{B}$, and $\mathrm{C}$, respectively. In this proposal, the decision making in inventory classification that best suits the conditions of the problem to be solved was left to the experts.

\section{Case Study}

This methodology was validated in a Colombian SME belonging to the graphic arts sector. This organization manufactures and distributes products such as labels, stickers, 


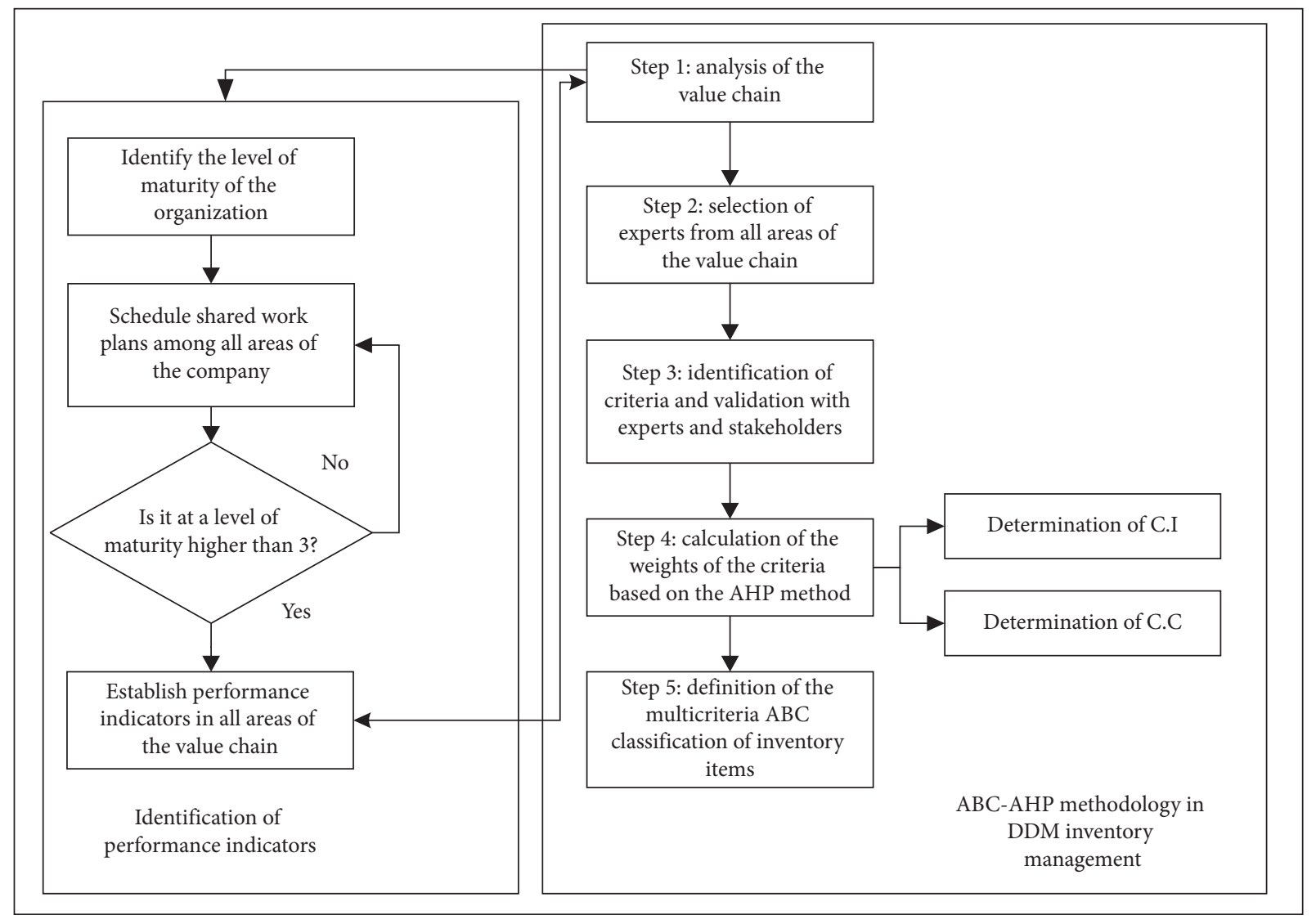

Figure 2: Proposed methodology.

leaflets, and different advertising materials. According to the information provided by the company, there were problems of shortages and supplies of raw materials. Moreover, the information among the areas related to the inventory management did not handle the same data about the level of stocks, costs, and dates of product delivery.

The following describes the implementation of the methodology in the case study.

\subsection{Steps 1 and 2: Value Chain Analysis and Selection of} Experts from All Areas of the Value Chain. An analysis of the value chain was conducted, following step 1 of the methodology as shown in Table 5, so interviews based on checklists about the process of inventory management of the company were made to the managers of planning, logistics, manufacturing, procurement, finance, and commercial areas (that make up the management team of the DDM). This management team was selected to act as the experts involved in inventory decision-making processes.

Table 6 presents the most representative results of the value chain analysis.

Table 7 shows the experts selected in step 2 .

As can be seen in Table 6, poor communication and lack of synergy among the areas related to the inventory process lead to problems, such as an imbalance in the plant, continuous breaches in the delivery of customers' orders, and deterioration of the image of the company. All these problems position the company below level 3 of maturity. In order for the company to reach level 3 , several meetings were necessary to address the communication problem, to share all the information related to inventory management, to unify points of view of the five areas involved, and to define the common objective of achieving a coordinated decision making. This common objective is to maximize compliance with the service level of the inventory items.

One of the aspects that stood out in the analysis of the value chain is that only one criterion is used to classify the inventory, leaving aside the perspective of other criteria that must be taken into account, such as lead time, criticality of the item, degree of substitutability, and distribution of demand, among others. It should be noted that prior to the application of this methodology, inventory items were classified only by the criterion unit cost. This is because there were items imported from Chile, which had a strong impact on the cash flow of the company, and therefore the general manager and the finance manager carried out the negotiation process with the suppliers.

The use of AHP as a multicriteria decision-making tool is highly relevant because it makes it possible to deal with the subjectivity and the pronouncement of expert judgments.

4.2. Steps 3 and 4: Determination of Criteria and Calculation of Their Weights Based on AHP Method. For the development of step 3, there were five stakeholders involved in the 
TABLE 5: Application of step 1 of the methodology (analysis of the value chain).

Analysis of the value chain (step 1)
The value chain of the company that covers all the functions of the company consists of suppliers, procurement, operations, marketing, sales, customers, human resources, and finance

The components of the value chain were used to lay the foundations for the performance indicators in inventory management

TABLE 6: Value chain analysis results.

\begin{tabular}{|c|c|}
\hline Areas & Value chain analysis results \\
\hline Inbound logistics & $\begin{array}{l}\text { There is no classification system by importance of inventory items } \\
\text { The logistics area classifies the products according to the rotation of the article, while the finance } \\
\text { area is based on the cost of acquisition } \\
\text { There are no inventory policies } \\
\text { The logistics area does not communicate in time to the procurement area the quantity of orders that } \\
\text { must be launched }\end{array}$ \\
\hline Operations & $\begin{array}{l}\text { There is a high rate of downtime in the plant due to the fact that there is no raw material to start the } \\
\text { daily production program } \\
\text { The sales area does not take into account the capacity of the plant when it comes to confirming } \\
\text { orders with customers, so they must pay overtime or subcontract units }\end{array}$ \\
\hline Outbound logistics & $\begin{array}{l}\text { Decreases in the indicator of correct deliveries due to noncompliance with customer delivery dates } \\
\text { There is continuous rescheduling of routes due to orders not being shipped on time }\end{array}$ \\
\hline Customers services & $\begin{array}{c}\text { There are decreases in the indicator of fulfilment of order delivery, since the finished product is } \\
\text { released late by the production area } \\
\text { The commercial area makes estimates using simple averages and does not take into account the } \\
\text { variability of demand }\end{array}$ \\
\hline Procurement & $\begin{array}{l}\text { There is no collaborative relationship with suppliers } \\
\text { Performance evaluation is not carried out for each provider }\end{array}$ \\
\hline $\begin{array}{l}\text { Information technology and } \\
\text { communications }\end{array}$ & An MRP system is being implemented to make more reliable production plans \\
\hline Human resources management & $\begin{array}{c}\text { Training is being programmed to improve communication among the members of the organization; } \\
\text { however, it is a process that takes a long time to show improvements }\end{array}$ \\
\hline Infrastructure & The company is acquiring new state-of-the-art equipment for printing processes \\
\hline
\end{tabular}

TABle 7: Application of step 2 of the methodology (selection of the experts).

The information comes from the opinion of experts with long experience and knowledge of the company: Selection of the experts (step 2) Planning manager, manufacturing manager, finance manager, logistics manager, and procurement manager.

inventory management process, selected in step 2 of the methodology. After the analysis of the value chain, the group of experts determined which factors were more important in inventory management of the company and defined the performance indicators. These performance indicators were defined in two participatory workshops through discussion and subsequent agreement. By consensus, the experts selected the performance indicators used to classify the inventory items from the list of criteria shown in Table 1.

With the collaboration of the experts, during two face-toface participatory workshops, 3 indicators were finally selected. The first session, in which the experts were shown the value chain and its key areas, lasted two hours. The session focused on the discussion about the key areas, particularly planning, manufacturing, finance, logistics and procurement, and the indicators associated with them. From this first session, 5 indicators were chosen: Unit cost, Lead time, Rotation, Criticality, and Substitutability. In the second session, the experts consensually expressed their interest in reducing the number of indicators to 3 , as can be seen in Table 8 .
In step 4, we proceeded to apply the AHP multicriteria method that resulted in the global priority vector of the criteria. This was calculated using the geometric mean to aggregate the priority vectors of the criteria of each of the 5 experts. The consistency of the decision-making process was also calculated in this step. These results are shown in Table 9.

At this stage, and through criteria comparison questionnaires answered by the experts, the degree of the importance among the criteria was obtained using Saaty's 1-9 scale [46].

An example of the questionnaire designed to allow the comparison analysis is shown in Figure 3.

The weights of the 3 criteria were obtained based on the geometric mean value of the priorities expressed by each expert.

According to the results presented in Table 9, we can observe that there is convergence among the results issued by the stakeholders, who prefer Unit cost as a predominant criterion for the classification of the items. However, the three most relevant criteria were considered to carry out the 
TABLE 8: Application of step 3 of the methodology (identification of criteria).

Unit cost: it is the acquisition cost of the inventory item measured in \$/unit.

Criteria (step

3) to the production area. It is measured in days.

Lead time: it is the time that elapses from when a purchase order is issued to the supplier until it is available to be delivered

Rotation: it is the number of times that an item of the inventory has been renewed in a period of time and is measured in number of times per year.

TABle 9: Application of step 4 of the methodology (AHP method results).

Calculation of criteria weights and consistency (step 4)

Unit cost: $38.31 \%$

Lead time: $33.80 \%$

Rotation: $27.89 \%$

C.I: 0.0042

R.I: 0.58

C.C: 0.007

With respect to the goal "to maximize compliance with the service level of the inventory items" for each pair of Inventory Management criterion, please indicate which of the two you consider to be most important and to what extent.

The inventory management criterion must be compared pairwise, by asking to what degree criterion

$\mathrm{C}_{i}$ has a greater importance compared with criterion $\mathrm{C}_{j}$, using the following scale (Saaty's scale):

$\mathrm{C}_{i j}=1$ : criterion $i$ and criterion $j$ are considered to be equally important

$\mathrm{C}_{i j}=3$ : criterion $i$ is considered to be slightly more important than criterion $j$

$\mathrm{C}_{i j}=5$ : criterion $i$ is considered to be significantly more important than criterion $j$

$\mathrm{C}_{i j}=7$ : criterion $i$ is considered to be far more important than criterion $j$

$\mathrm{C}_{i j}=9$ : criterion $i$ is considered to be absolutely more important than criterion $j$

C1: Unit cost

C2: Lead time

\begin{tabular}{|l|c|c|c|c|c|}
\hline $\begin{array}{l}\text { Which Inventory Management Criterion do you consider more } \\
\text { important? }\end{array}$ & C1 & C2 & \multicolumn{4}{|l|}{} \\
\hline To what extent? & 1 & 3 & 5 & 7 & 9 \\
\hline
\end{tabular}

FIgURE 3: Sample of questionnaire used for comparison of criteria.

$\mathrm{ABC}$ classification, since they were performance measurement indicators common to all areas of the value chain and accepted by consensus among all the stakeholders in those areas.

As can be seen in Table 9, there is a convergence between the judgments issued by the experts, given that the consistency coefficient (C.C) is less than 0.1. Additionally, the most important criterion is Unit cost with $38.31 \%$. This occurs because there is a strong preference of the finance and procurement managers towards this criterion, which prioritizes the purchase to the lowest cost suppliers. Lead time criterion with $33.80 \%$ occupies the second position and has a strong preference of the logistics and planning managers, due in large part to the fact that low levels of inventory lead to unreliability of production plans.

4.3. Step 5: Multicriteria ABC Classification. In this step, the items were ordered based on the level of compliance of each item for the 3 criteria, thus obtaining the results of Table 10 .
TABLE 10: Multicriteria ABC Classification results.

\begin{tabular}{lccc}
\hline Class & Items & Percentage & Weighted score \\
\hline A & 32 & 19.75 & $>0.14$ \\
B & 49 & 30.24 & $>0.083$ \\
C & 81 & 50.00 & $>0.05$ \\
Total & 162 & 100 & \\
\hline
\end{tabular}

The results of the prioritization of the items according to inventory management criteria lead to categorizing the items in $\mathrm{ABC}$ classes. This prioritization was calculated by means of the weighted sum of the values of each item for each criterion, as explained in Table 11.

It is important to note that the company has 453 items, of which 162 are classified as critical within the manufacturing process. The development of this proposal was applied to these 162 items of the total handled by the company.

Table 10 shows the representative results of this step. 
TABLE 11: Application of step 5 of the methodology (multicriteria ABC classification).

To classify the inventory items, the values of each item for each criterion must be normalised and multiplied by their

Multicriteria

ABC Classification

(step 5) corresponding weights resulting from the AHP method. Later, the items were ordered in descending order of the weighted score and groups $\mathrm{A}, \mathrm{B}$, and $\mathrm{C}$ were established by the experts (see table in the supplementary material (STEP5_ABC CLASSIFICATION)).

\section{Conclusions}

The customer service orientation approach requires cooperation at the operational level in the company and even the entire supply chain to improve delivery times, as well as flexibility in some processes and efficiency in the performance of the operation. A better synchronization means lower costs throughout the chain, a high level of quality, and an improvement in the image of the organization. However, the synchronization of all members of an organization is not an easy task because there must be shared information, as well as communication and coordination among all the areas of the company. The value chain analysis can be used as a theoretical framework to identify the main areas that need coordination to solve a problem within the organization.

This research work describes a new methodology, based on analytic hierarchy process (AHP), to solve problems in inventory management distributed decision making (DDM) involving all areas of the company. This approach evaluates the performance in inventory management of companies in a trustworthy and efficient way. It covers an indicator selection process adapted to the company using value chain analysis.

The approach combines the use of an AHP multicriteria group decision-making technique with value chain analysis to identify performance indicators for all areas of the company that can be used as criteria for ranking items in ABC inventory classification. The methodology includes all the stakeholders involved in the decision-making process, considering the different information and perspectives they have. These different perspectives depend on the area to which each one belongs. AHP is used due to its ability to obtain quantitative values from the qualitative opinions of the experts and also because it allows the aggregation of the priorities of the selected experts. The experts were selected according to their experience and knowledge in the different areas of the company's value chain (management team). They are treated as a single decision-making unit (DMU) since they share the same objective in terms of inventory management.

The analysis of the value chain of companies helps to identify the first performance indicators of the areas of the company related to inventory management. These performance indicators will then be weighted with the implementation of AHP in the proposed methodology. For its validation, the methodology was applied to a company in the graphic arts sector of Colombia.
The weighting of the criteria (indicators) provides some important insights into the general philosophy and the underlying conception of the experts on inventory management. The data resulting from the indicators show that the most important criterion in $\mathrm{ABC}$ inventory classification is Unit cost because there is a strong preference of the finance and procurement managers for this criterion. The second one is Lead time which is strongly preferred by managers of logistics and planning.

The results obtained from the analysis of the company's value chain diagnosed the lack of communication and coordination among the different areas and proposed improvement actions aligned with the objective of the decision problem. These improvement actions allow the company to connect inventory management processes with other areas and are necessary for any organization that shares common objectives in a coordinated decision making. A single-level distributed inventory control approach was used with the decisions made by all the stakeholders involved at the management team level, allowing communication among the decision makers.

The experts agreed on the selection of most of the indicators, but not on the weights assigned to the indicators. However, all five experts agreed with the final result obtained through the aggregation of their priorities and with the procedure followed in the methodology. The case study showed that the geometric mean proposed by AHP to add priorities helps to balance the extreme positions among the decision makers and is useful in the cases of team-based DDM systems (which are like one-party systems with a single DMU).

Based on the findings of this study, we can conclude that it is not so important for an organization to measure the performance in the inventory management of all areas of the company's value chain. On the contrary, it is relevant for any organization to have clear objectives, the criteria of prioritization in the classification of items and their corresponding weights, since this contributes directly to reaching the objective. The AHP method contributes efficiently to solve a multicriteria decision-making process with several stakeholders from the different areas involved in the company, and the results obtained in this work allow us to conclude that AHP is an adequate tool for ABC inventory classification.

Even though the new proposal has been applied specifically to the graphic arts sector, this tool can be adapted to any industrial sector, provided that the criteria are correctly identified. This tool constitutes a very promising line of future research in the field of distributed decision making in inventory management.

\section{Limitations and Future Work}

Some limitations of this work must be pointed out. On the one hand, a limitation of this approach is that classifying thousands of items with respect to several criteria is a complex and time-consuming task. Machine learning approaches like support vector machines and deep neural networks [43] can help to overcome this issue. 
On the other hand, another limitation could be treating $\mathrm{ABC}$ inventory classification as a ranking problem, not as a sorting problem. In the case of this paper, the experts decided the final sorting step, including each item in a critical class (A, B, or $\mathrm{C})$. The following situation could have occurred: two items with exactly the same score could have been in two different clusters. This method is conditioned [31] by the subjective opinion of the experts on the criticality of the item.

Accordingly Ishizaka and Nemery [55], inventory item classification requires a sorting method. This last issue could constitute a subject for further research. We propose the use of AHPSort [27] in a future work, applying this method to the same set of items. In this way, we can compare the results obtained and present these new results to the managers in order to achieve their approval. Although, a priori, a larger number of meetings with the experts are necessary to agree on the limiting profiles of the classes, the level of satisfaction with the results is likely to be higher due to the overall time savings. However, they can see that with the limiting profiles established in advance, the classification decision achieves greater objectivity.

\section{Data Availability}

The multicriteria ABC classification data used to support the findings of this study are included within the supplementary information file.

\section{Conflicts of Interest}

The authors declare that there are no conflicts of interest regarding the publication of this paper.

\section{Supplementary Materials}

This file consists of an excel file with two calculation sheets: (i) STEPS 3 AND 4_AHP METHOD: with the data of the pairwise comparison matrices used by the experts for the calculation of the criteria weights and (ii) STEP 5_ABC CLASSIFICATION: with the data of the items' values for each criterion used for the ABC inventory classification. (Supplementary Materials)

\section{References}

[1] R. Poveda-Bautista, D. C. Baptista, and M. Garca-Melón, "Setting competitiveness indicators using BSC and ANP," International Journal of Production Research, vol. 50, no. 17, 2012.

[2] R. Ballou, Administración de la Cadena de Suministro, Casa del Libro, Barcelona, Spain, 2004.

[3] O. Parada, "Un enfoque multicriterio para la toma de decisiones en la gestión de inventario," Cuadernos de Administracion.vol. 22, pp. 169-187, 2009.

[4] C. A. Castro Zuluaga, M. C. Velez Gallego, and J. A. Catro Urrego, "Clasificación ABC multicriterio: tipos de Criterios y efectos en la asignación de pesos," ITECKNE, vol. 8, no. 2, pp. 163-170, 2014.

[5] T. Saaty, "The analytic hierarchy process-what it is and how it is used," Science Direct, vol. 9, no. 3-5, pp. 161-176, 1987.
[6] M. Porter, Competitive Advantage: Creating and Sustaining Superior Performance, Free Press, New York, NY, USA, 1985.

[7] E. A. Morash and S. R. Clinton, "Supply chain integration: customer value through collaborative closeness versus operational excellence," Journal of Marketing Theory and Practice, vol. 6, no. 4, pp. 104-120, 1998.

[8] R. M. Ilyas and R. Shankar, "Value chain relationship-a strategy matrix," Supply Chain Forum: An International Journal, vol. 7, pp. 56-72, 2006.

[9] N. Fabbe-Costes, "Évaluer la création de valeurdu supply chain management," Logistique \& Management, vol. 23, no. 4, pp. 41-50, 2015.

[10] M. Porter, Ventaja Competitiva:, CECSA, Norma, México, 1995.

[11] M. J. Spendolini, Benchmarking, CECSA, Bogotá, Colombia, 1st edition, 1994.

[12] B. E. Flores and D. Clay Whybark, "Multiple criteria ABC analysis," International Journal of Operations \& Production Management, vol. 6, no. 3, pp. 38-46, 1986.

[13] E. A. Silver, D. F. Pyke, and R. Peterson, Inventory Management and Production Planning and Scheduling, John Wiley \& Sons, New York, NY, USA, 3rd edition, 1998.

[14] F. Y. Partovi and J. Burton, "Using the analytic hierarchy process for ABC analysis," International Journal of Operations \& Production Management, vol. 13, no. 9, pp. 29-44, 1993.

[15] K. Balaji and V. S. S. Kumar, "Multicriteria inventory ABC classification in an automobile rubber components manufacturing industry," Procedia CIRP, vol. 17, pp. 463-468, 2014.

[16] M. Stojanović and D. Regodić, "The significance of the integrated multicriteria ABC-XYZ method for the inventory management process," Acta Polytechnica Hungarica, vol. 14, no. 5, pp. 29-48, 2017.

[17] R. Ramanathan, "ABC inventory classification with multiplecriteria using weighted linear optimization," Computers \& Operations Research, vol. 33, no. 3, pp. 695-700, 2006.

[18] T. J. Van Kampen, R. Akkerman, and D. Pieter van Donk, "SKU classification: a literature review and conceptual framework," International Journal of Operations \& Production Management, vol. 32, no. 7, pp. 850-876, 2012.

[19] B. E. Flores, D. L. Olson, and V. K. Dorai, "Management of multicriteria inventory classification," Mathematical and Computer Modelling, vol. 16, no. 12, pp. 71-82, 1992.

[20] P. P. Gajpal, L. S. Ganesh, and C. Rajendran, "Criticality analysis of spare parts using the analytic hierarchy process," International Journal of Production Economics, vol. 35, no. 13, pp. 293-297, 1994.

[21] N. M. Scala, J. Rajgopal, and K. L. Needy, "Managing nuclear spare parts inventories: a data driven methodology," IEEE Transactions on Engineering Management, vol. 61, no. 1, pp. 28-37, 2014.

[22] F. Y. Partovi and W. E. Hopton, "The analytic hierarchy process as applied to two types of inventory problems," Production and Inventory. Management. Journal, vol. 35, pp. 13-29, 1994.

[23] Y. Hadad and B. Keren, "ABC inventory classification via linear discriminant analysis and ranking methods," International Journal of Logistics Systems and Management, vol. 14, no. 4, pp. 387-404, 2013.

[24] H. A. Guvenir and E. Erel, "Multicriteria inventory classification using a genetic algorithm," European Journal of Operational Research, vol. 105, no. 1, pp. 29-37, 1998.

[25] J. Rezaei and S. Dowlatshahi, "A rule-based multi-criteria approach to inventory classification," International Journal of Production Research, vol. 48, no. 23, pp. 7107-7126, 2010. 
[26] S. M. Hatefi, S. A. Torabi, and P. Bagheri, "Multi-criteria ABC inventory classification with mixed quantitative and qualitative criteria," International Journal of Production Research, vol. 52, no. 3, pp. 776-786, 2014.

[27] A. Ishizaka, C. Pearman, and C. Nemery, "AHPSort: an AHPbased method for sorting problems," International Journal of Production Research, vol. 50, no. 17, pp. 4767-4784, 2012.

[28] M.-C. Yu, "Multi-criteria ABC analysis using artificial-intelligence-based classification techniques," Expert Systems with Applications, vol. 38, no. 4, pp. 3416-3421, 2011.

[29] C.-Y. Tsai and S.-W. Yeh, "A multiple objective particle swarm optimization approach for inventory classification," International Journal of Production Economics, vol. 114, no. 2, pp. 656-666, 2008.

[30] G. Aydin Keskin and C. Ozkan, "Multiple criteria ABC analysis with FCM clustering," Journal of Industrial Engineering, vol. 2013, Article ID 827274, 7 pages, 2013.

[31] F. Lolli, A. Ishizaka, and R. Gamberini, "New AHP-based approaches for multi-criteria inventory classification," International Journal of Production Economics, vol. 156, pp. 62-74, 2014.

[32] A. M. L. Raja, T. J. Ai, and R. D. Astanti, "A clustering classification of spare parts for improving inventory policies," IOP Conference Series: Materials Science and Engineering, vol. 114, 2016.

[33] F. M. Zowid, M. Z. Babai, M. R. Douissa, and Y. Ducq, "Multicriteria inventory $\mathrm{ABC}$ classification using gaussian mixture model," IFAC-PapersOnLine, vol. 52, no. 13, pp. 1925-1930, 2019.

[34] M. Z. Babai, T. Ladhari, and I. Lajili, "On the inventory performance of multi-criteria classification methods: empirical investigation," International Journal of Production Research, vol. 53, no. 1, pp. 279-290, 2015.

[35] T. Jelassi and G. Kersten, "An introduction to group decision and negotiation support," in Readings in Multiple Criteria Decision Aid, C. A. Bana Costa, Ed., Springer, Berlin, Germany, 1990.

[36] C. Schneeweiss, "Distributed decision making-a unified approach," European Journal of Operational Research, vol. 150, no. 2, pp. 237-252, 2003.

[37] P. M. Pardalos, Y. Siskos, and C. Zopounidis, Advances in Multicriteria Analysis, Kluwer Academic Publishers, Dordrecht, Netherlands, 1995.

[38] T. L. Saaty and K. Peniwati, Group Decision Making. Drawing Out and Reconciling Differences, RWS Publications, Pittsburgh, PA, USA, 2008.

[39] T. L. Saaty, "Decision making with the analytic hierarchy process," International Journal of Services Sciences, vol. 1, no. 1, pp. 83-98, 2008.

[40] O. Cakir and M. S. Canbolat, "A web-based decision support system for multi-criteria inventory classification using fuzzy AHP methodology," Expert Systems with Applications, vol. 35, no. 3, pp. 1367-1378, 2008.

[41] J. Liu, X. Liao, W. Zhao, and N. Yang, "A classification approach based on the outranking model for multiple criteria ABC analysis," Omega, vol. 61, pp. 19-34, 2016.

[42] M. R. Douissa and K. Jabeur, "A new model for multi-criteria ABC inventory classification: PROAFTN method," Procedia Computer Science, vol. 96, pp. 550-559, 2016.

[43] F. Lolli, E. Balugani, A. Ishizaka, R. Gamberini, B. Rimini, and A. Regattieri, "Machine learning for multi-criteria inventory classification applied to intermittent demand," Production Planning \& Control, vol. 30, no. 1, pp. 76-89, 2019.
[44] H. Kartal, A. Oztekin, A. Gunasekaran, and F. Cebi, "An integrated decision analytic framework of machine learning with multi-criteria decision making for multi-attribute inventory classification," Computers \& Industrial Engineering, vol. 101, pp. 599-613, 2016.

[45] D. López-Soto, F. Angel-Bello, S. Yacout, and A. Alvarez, "A multi-start algorithm to design a multi-class classifier for a multi-criteria ABC inventory classification problem," Expert Systems with Applications, vol. 81, pp. 12-21, 2017.

[46] T. L. Saaty, Fundamentals of Decision Making and Priority Theory with the Analytic Hierarchy Process, RWS Publications, Pittsburgh, PA, USA, 2000.

[47] F. Dweiri, S. Kumar, S. A. Khan, and V. Jain, "Designing an integrated AHP based decision support system for supplier selection in automotive industry," Expert Systems with Applications, vol. 62, pp. 273-283, 2016.

[48] G. Bruno, E. Esposito, A. Genovese, and M. Simpson, “Applying supplier selection methodologies in a multi-stakeholder environment: a case study and a critical assessment," Expert Systems with Applications, vol. 43, pp. 271-285, 2016.

[49] J. Bravo, J. Osorio, and J. Orejuela, "Modelo para la priorización dinámica de despachos de vehículos utilizando el proceso analítico jerárquico dynamic priorization model of dispatching vehicles using analytic hierarchy process," RICYDE. Revista internacional de ciencias del deporte, vol. 48, pp. 201-215, 2009.

[50] P. Guarnieri, V. A. Sobreiro, M. S. Nagano, and A. L. Marques Serrano, "The challenge of selecting and evaluating thirdparty reverse logistics providers in a multicriteria perspective: a Brazilian case," Journal of Cleaner Production, vol. 96, pp. 209-219, 2015.

[51] A. Ishizaka and A. Labib, "Review of the main developments in the analytic hierarchy process," Expert Systems with Applications, vol. 38, no. 6, pp. 14336-14345, 2011.

[52] F. Y. Partovi and M. Anandarajan, "Classifying inventory using an artificial neural network approach," Computers \& Industrial Engineering, vol. 41, no. 4, 2002.

[53] M. Alonso-Manzanedo, M. V. De-la-Fuente-Aragon, and L. Ros-McDonnell, "A proposed collaborative network enterprise model in the fruit-and-vegetable sector using maturity models," in Annals of Industrial Engineering 2012, pp. 359-366, Springer, Berlin, Germany, 2014.

[54] M. Augusto, J. Lisboa, M. Yasin, and J. R. Figueira, "Benchmarking in a multiple criteria performance context: an application and a conceptual framework," European Journal of Operational Research, vol. 184, no. 1, pp. 244-254, 2008.

[55] A. Ishizaka and P. Nemery, Multi-criteria Decision Analysis: Methods and Software, John Wiley \& Sons, Hoboken, NJ, USA, 2013. 